\title{
Frog eat frog: exploring variables influencing anurophagy
}

G John Measey, Giovanni Vimercati, F André de Villiers, Mohlamatsane M Mokhatla, Sarah J Davies, Shelley Edwards, Res Altwegg

Background Frogs are generalist predators of a wide range of typically small prey items. But descriptions of dietary items regularly include other anurans, such that frogs are considered to be among the most important of anuran predators. However, the only existing hypothesis for the inclusion of anurans in the diet of post-metamorphic frogs postulates that it happens more often in bigger frogs. Moreover, this hypothesis has yet to be tested. Methods We reviewed the literature on frog diet in order to test the size hypothesis and determine whether there are other putative explanations for anurans in the diet of post-metamorphic frogs. In addition to size, we recorded the habitat, the number of other sympatric anuran species, and whether or not the population was invasive. We controlled for taxonomic bias by including the superfamily in our analysis.

Results Around one fifth of the 355 records included anurans as dietary items of populations studied, suggesting that frogs eating anurans is not unusual. Our data showed a clear taxonomic bias with ranids and pipids having a higher proportion of anuran prey than other superfamilies. Accounting for this taxonomic bias, we found that size in addition to being invasive, local anuran diversity, and habitat produced a model that best fitted our data. Large invasive frogs that live in forests with high anuran diversity are most likely to have a higher proportion of anurans in their diet. Conclusions We confirm the validity of the size hypothesis for anurophagy, but show that there are additional significant variables. The circumstances under which frogs eat frogs are likely to be complex, but our data may help to alert conservationists to the possible dangers of invading frogs entering areas with threatened anuran species. 
G. John Measey ${ }^{* 1}$, Giovanni Vimercati ${ }^{1}, F$. André de Villiers ${ }^{1}$, Mohlamatsane M. Mokhatla ${ }^{1}$,

4 Sarah. J. Davies ${ }^{1}$, Shelley Edwards ${ }^{1} \&$ Res Altwegg ${ }^{2,3}$

$6{ }^{1}$ Centre for Invasion Biology, Department of Botany \& Zoology, Stellenbosch University,

7 Stellenbosch, South Africa

8 2Statistics in Ecology, Environment and Conservation, Department of Statistical Sciences,

9 University of Cape Town, Rondebosch, Cape Town, South Africa

$10{ }^{3}$ African Climate and Development Initiative, University of Cape Town

*Corresponding author: G. John Measey, Centre for Invasion Biology, Department of Botany \& Zoology, Stellenbosch University, Stellenbosch, South Africa. Tel: +27 21808 2385; email: john@measey.com

\section{Abstract}

Background

Frogs are generalist predators of a wide range of typically small prey items. But descriptions of dietary items regularly include other anurans, such that frogs are considered to be among the most important of anuran predators. However, the only existing hypothesis for the inclusion of anurans in the diet of post-metamorphic frogs postulates that it happens more often in bigger frogs. Moreover, this hypothesis has yet to be tested.

\section{Methods}

We reviewed the literature on frog diet in order to test the size hypothesis and determine whether there are other putative explanations for anurans in the diet of post-metamorphic frogs. In addition to size, we recorded the habitat, the number of other sympatric anuran species, and whether or not the population was invasive. We controlled for taxonomic bias by including the superfamily in our analysis.

Results

Around one fifth of the 355 records included anurans as dietary items of populations studied, suggesting that frogs eating anurans is not unusual. Our data showed a clear taxonomic bias with ranids and pipids having a higher proportion of anuran prey than other superfamilies.

33 Accounting for this taxonomic bias, we found that size in addition to being invasive, local anuran 34 diversity and habitat produced a model that best fitted our data. Large invasive frogs that live in 
35 forests with high anuran diversity are most likely to have a higher proportion of anurans in their 36 diet.

37 Conclusions

38 We confirm the validity of the size hypothesis for anurophagy, but show that there are additional 39 significant variables. The circumstances under which frogs eat frogs are likely to be complex, 40 but our data may help to alert conservationists to the possible dangers of invading frogs 41 entering areas with threatened anuran species.

42

43 Key Words: Anura, anurophagy, cannibalism, habitat, invasive, predation, size relationships 44

45 


\section{Introduction}

Amphibians are mostly dietary generalists. Most adult amphibians, whether they be frogs, salamanders or caecilians, consume a wide range of small invertebrate prey items (e.g. Wells 2007). While the position of some amphibians in trophic webs has been shown to be important, the position and/or importance of the vast majority of species is unknown (Altig et al. 2007; Halliday 2008). However, amphibians can achieve a surprisingly high biomass in some environments (Gibbons et al. 2006; Woolbright et al. 2006), and adult life history stages can be the most abundant vertebrate in some, particularly forested, ecosystems (Burton \& Likens 1975; Semlitsch et al. 2014). The aquatic larval stages often dominate small freshwater ecosystems both as important consumers of primary producing algae, and sometimes higher up the trophic food web (Colón-Gaud et al. 2009; Verburg et al. 2007). Due to their complex life histories, amphibians also link aquatic and terrestrial food webs both as predators and as prey (Kraus et al. 2011; McCoy et al. 2009; Regester et al. 2006). It follows then that as important members of the ecosystem and dietary generalists, amphibians may also be food for each other. Among such instances, frogs eating frogs are often the subject of anecdotal observations (see Toledo et al. 2007). However, there have been relatively few studies to show how widespread this is, and few hypotheses to suggest which frogs may be the most important predators of other anurans.

Being able to test the role of various different hypotheses on anuran predation would help clarify the importance of the role of frogs as predators of other anurans. This is of especially high importance when assessing the threats posed by invasive frogs to local populations, and predicting the effects of emerging invasive species. Perhaps of increasing relevance due to widespread amphibian declines is the need to predict the effects of loss of indigenous species to a species assemblage. Several authors have commented on the negative effects of invasive amphibians on populations of native anurans (Kats \& Ferrer 2003; Wells 2007), and while these are sometimes multiple and complex threats (Kats \& Ferrer 2003; Kiesecker 2003), they often include predation of native adult anurans by invasive frogs (Boelter et al. 2012). In a recent review, Bucciarelli et al. (2014) found that, along with plants and fishes, introduced amphibians are one of the groups that significantly affect indigenous amphibian populations.

Around $80 \%$ of predators are larger than their prey, and the relationship of body sizes between predators and their prey is a central tenet in food webs and their stability (Brose et al. 2006; Cohen et al. 1993). However, it appears that different habitats are not equal, with freshwater 
lakes and streams having higher predator-prey body-size ratios, something that could be linked to the gape limited nature of aquatic predators (Brose et al. 2006). Size differentials between amphibians and their prey appear to conform to this (Caldwell \& Vitt 1999), but the indeterminate nature of amphibian growth promotes cohort dominance through predation of con- and heterospecifics (Wakano et al. 2002; Woodward et al. 2005). Toledo et al. (2007) suggested that the predator-prey size relationship is the most important predictor of anuran predation, such that larger species are capable of switching from being prey items to becoming predators. Similarly, Wells (2007) asserted that size is perhaps the most important predictor of adult frog predation on other anurans.

Amphibians inhabit a diverse array of habitats, and it seems likely that the availability of anurans as prey depends, in part, on the habitat that they occur in. For example, forests are complex habitats where anurans are capable of partitioning their space into three dimensions, including arboreal, leaf litter, aquatic and water-side guilds ( $c f$ Williams \& Hero 1998). However, even within guilds it appears that multiple species are capable of dividing up resources (Caldwell \& Vitt 1999; Toft 1985). Savannahs represent more two dimensional habitats where frogs might be more likely to encounter other anurans. Similarly, frogs may encounter more anuran prey in locations where there is more anuran diversity; either because increased diversity is likely to include heterospecifics that are small enough to be prey items, and/or as species are likely to move into the same physical space: i.e. frogs that are convenience predators eat anurans.

In this study, we aim to test the hypothesis that a frog's body size is a predictor of the proportion of anuran prey in its diet. In addition, we seek a signal that may result from the habitat that the amphibians occur in, and whether there is a relationship between the diversity of anurans in the environment, and anuran predation. Lastly, we investigate whether or not invasive frogs are more likely to be anuran predators. In order to test our competing hypotheses, we compile a dataset of post-metamorphic anuran diet data from the literature. Our response variable is set at the population level as the proportion of the diet that was made up of anuran amphibians. We assume that there may be a taxonomic bias in the amphibian predators, based on correlations of skull shape with diet (Emerson 1985) and therefore include sperfamily in the analysis.

\section{Materials \& Methods}

In order to obtain literature, we searched ISI Web of Science and Google Scholar for publications with 'topic' (for the former) or search terms 'in the title of the article' (for the latter) 
114 containing: 'frog OR Anura' and 'diet' OR 'food'. We attempted to obtain all resulting papers and

115 for each extracted a fixed set of data (below). Additional papers were added based on our

116 expert knowledge, or through correspondence with authors.

118 Studies were included in the dataset if they contained information on diet of at least 20 post-

119 metamorphic anurans representing a sample of a population of the same species from a single

120 defined locality. In addition we required that a complete set of the following variables could be

121 extracted: coordinates of study site; species name; number of individuals examined; total prey

122 items; total anurans eaten (divided into eggs, larvae and post-metamorphic individuals). We

123 also recorded the mean snout-vent length (SVL) if reported. If SVL data was missing, we

124 generated a typical SVL (to the nearest $\mathrm{mm}$ ) for the species from a variety of sources (e.g.

125 guidebooks, Amphibiaweb). If studies reported on the diet of more than a single species, we

126 included each species as a separate entry, provided that all information was discretely reported.

127 In addition, we recorded the species of anuran eaten (if any), whether ingestion was reported as

128 cannibalism alone, or mixed with other species. We defined 'cannibalism' as evidence that a

129 frog had eaten a conspecific, irrespective of the life-history stage: i.e. egg, tadpole or post-

130 metamorphic individual of the same species. We also recorded if the species studied was

131 considered invasive (or not) at the site where the study was conducted, this was then later

132 corroborated with the Global Amphibian Assessment (GAA) database (see below).

133

134 Taxonomy

135 We used current taxonomic nomenclature according to Frost (2015). We updated taxonomic

136 entities when possible and checked validity of identification with distribution data (see below). In

137 cases where the published species identification could not be verified, we removed the record

138 from the dataset. To test for the influence of taxonomy on anuran predation, we grouped

139 families into superfamilies, because some families were represented only by a single

140 observation. We used a recent phylogeny of all Amphibia to group families at well supported

141 nodes (Pyron 2014; Pyron \& Wiens 2011): Discoglossoidea, Hyloidea, Pelobatoidea, Pipoidea,

142 Leiopelmatoidea and Ranoidea (see Pyron 2014 for contents of superfamilies).

143

144 Habitat

145 For each species in our dataset, we assigned a habitat value based on that reported in the

146 IUCN database. We followed Ficetola et al. (2015) in assigning species to one of four habitat

147 categories: forest specialists, grassland, shrubland and generalists. Species were scored as 
148 generalists if their entry in the IUCN database mentioned that they could be found in more than

149 one habitat category.

150

Number of anuran species at the study site

152 To estimate anuran species diversity at each study site, we took the locality record of the study

153 site, converted it to decimal degrees to create a layer of all the studies for which we had locality

154 data, using ArcMap GIS 10.2. This layer was then overlaid with the anuran species range maps

155 obtained from the IUCN Global Amphibian Assessment dataset

156 (http://www.iucnedlist.org/amphibians; GAA version 3.1), using the extent of occurrence

157 shapefiles as "known distributions". After noting the number of species at each site, we cross-

158 checked coordinates given in manuscripts with species studied or mentioned within to ascertain

159 a correct locality and accurate species identification, and these were reconciled with the GAA

160 list. Occasionally, coordinates did not correspond with GAA presence, and these were double-

161 checked and if locality or species identification could not be verified with reference to the GAA

162 list, the record was removed from the dataset.

163

164 Analyses

165 From each record, we calculated the total number of 'anurans eaten' (eggs + larvae + post-

166 metamorphic individuals), the number of prey eaten that were 'not anurans' (total prey - anurans

167 eaten). These were combined to make our response variable: ('anurans eaten', 'not anurans').

168 We analysed these data using generalised linear models (GLM) with binomial errors and a logit

169 link function implemented in the function ' $\mathrm{glm}$ ' in R 3.2.1 (R Core Team 2015) using our

170 response variable and our variables of interest (habitat, invasiveness, SVL and species

171 diversity) as explanatory variables. None of the explanatory variables were strongly correlated

172 with each other $(r<0.4)$. In a preliminary analysis, we established that superfamily was a

173 significant effect, so we included this term in each model. We also assessed whether the

174 number of individuals in the study had a positive relationship with finding anurans in the diet.

175

176 We fitted 15 models to the data, representing all possible combinations of the four explanatory

177 variables of interest. We had no prior reason for thinking that there may be interactions between

178 these variables and therefore only fitted main effects. We ranked the models using Akaike's

179 Information Criterion (AIC). The coefficients in the models we used are estimated as the

180 logarithm of the odds ratio. We report these and also the odds ratios. 
182

183

184

185

186

187

188

189

190

191

192

193

194

195

196

197

198

199

200

201

202

203

204

205

206

207

208

209

210

211

212

213

214

\section{Results}

Our literature search yielded 1308 items, and from these we were able to find 323 papers in which all of our variables could be sourced. Since some studies reported data on multiple species, we had a dataset of 355 records from 228 species. These included the contents of 40 238 anuran stomachs with some 456146 prey items, of which 1711 were anuran eggs (29\%), larvae $(21 \%)$ and post-metamorphs $(50 \%)$. The majority of records revealed that most populations of frogs did not consume any anuran life-history stages $(n=278)$. However, over a fifth of records $(n=77)$ reported predation of eggs, larvae or post-metamorphic individuals, indicating that Anura are not a rare or unusual dietary item in frog populations. However, when frogs did eat other anurans, the mean proportion of amphibian prey was only $2.9 \%$ of total prey items (max. 18.5\%).

Our initial analyses revealed a significant effect of superfamily on predation of anurans, whereby members of Ranoidea and Pipoidea were significantly more likely to eat anurans than were the other superfamilies (Fig 1, Likelihood Ratio Test: chi-square $=1387$, df $=4, P<0.001$ ). To account for this in subsequent analyses we included superfamily as a fixed effect in each GLM. It is noteworthy that when only post-metamorphic prey items were included, the significant effect of the pipids fell away leaving ranids as the only significant superfamily (results not shown). However, we found no increase in detection of anurophagy with increasing number of individuals in each study $(P=0.137)$, this suggests that we were successful in avoiding sampling bias by restricting studies to those with 20 individuals or more.

The most parsimonious model included all of our variables: body size, habitat type, invasive species and diversity at the study site (Model 'spp + habitat + invasive + SVL', Table 1). A single model was within four delta AIC units of the best model (Model 'SVL + spp + invasive'). The proportion of anurans eaten was significantly influenced by size (effect on the logit scale: 0.028 , se $=0.001$; odds ratio $=1.028$, i.e. for every $\mathrm{mm}$ increase in $\mathrm{SVL}$, the species is $2.8 \%$ more likely to eat other anurans), invasive species (effect of being invasive 0.336 , se $=0.075$; odds ratio $=1.400$, i.e. invasive frogs were $40 \%$ more likely to eat anurans), the number of species at the study site $(0.017, \mathrm{se}=0.001$; odds ratio $=1.017$, i.e. for every additional species occurring at the study site, frogs were $1.7 \%$ more likely to eat anurans), and habitat (Fig 2: this effect was mainly driven by frog generalists being more likely to eat anurans than frogs from forest habitat, with frogs from forest, grassland and shrubland similar to one another: grassland vs forest - 
2150.029 , se $=0.188$, odds ratio $=0.971$, i.e. grassland frogs were $97.1 \%$ less likely to eat anurans 216 than forest species).

218 In addition, we considered whether cannibalism was a major factor in studies where frogs were 219 found eating other anurans. Cannibalism was identified in 28 of the records that we analysed.

220 Another 28 could have been examples of cannibalism, but the identity of the anuran eaten was 221 not specified. We thus classified interactions as cannibalistic, possibly cannibalistic and not 222 cannibalistic. In those studies where frogs ate other anurans, cannibals were not found to have 223 a greater proportion of anurans in their diet (Likelihood Ratio Test: Chi-square $=0.0014$; $224 \mathrm{df}=2,74 ; \mathrm{P}=0.3985)$.

225

\section{Discussion}

Our data shows that size is a dominant predictor of anurophagy in populations of postmetamorphic frogs, confirming existing hypotheses to this effect. However, the best model fitting our data included all three additional variables to best explain the presence of anurans in the diet of other anurans; frogs eating frogs. We found that a model including size, habitat, invasiveness and the diversity of anurans at the study site was the best model. We discuss these four explanatory variables separately first, before considering how they may act together.

Body size

Although it seems obvious that larger species are more likely to consume other anurans, and our results are in accordance with this, we found a number of studies that did not fit this model. For example, very small frogs are capable of consuming the eggs of other species (Beard 2007; Drewes \& Altig 1996). In addition, juveniles of species that attain a large adult size can eat a large proportion of anurans. For example, Glorioso et al. (2012) found that nearly all size classes of the Cuban treefrog (Osteopilus septentrionalis) ate other anurans, from under $40 \mathrm{~mm}$ to $83 \mathrm{~mm}$. Similarly, Conradie et al. (2010) found that juveniles of Pyxicephalus adspersus had eaten many other small anurans, even though their own mean body size was under $40 \mathrm{~mm}$ (see also Schalk et al 2014). This species has a very large gape, and it has been suggested elsewhere (Boelter et al. 2012; Emerson 1985; Konopik et al. 2014; Schalk \& Fitzgerald 2015) that gape size may be as important as overall size in consumption of anurans. We suggest that this will be a fruitful area for future research on anurophagy. We also found a number of very large frogs which had no anurans in their diet, many of which were toads (see below). 
We found that the number of species present at the site in which the dietary study was conducted had a positive relationship with the proportion of anurans in the diet. This result is somewhat intuitive, and might be best explained by increasing diversity resulting in increased numbers of anurans which are of a relevant size, and/or acting as a proxy for an increased abundance of amphibians in the ecosystem. Due to the nature of the data, we were not able to investigate the density of amphibians at the time that they were sampled. We expect that density of prey species would almost certainly play a role (see Polis \& Myers 1985), but this was very rarely, if ever, reported in the dietary papers that we studied. Amphibian diversity increases markedly in the tropics (Bonetti \& Wiens 2014; Hof et al. 2011), often in forested areas, and it may be that our finding correlates with a number of other untested variables including an increase in ambient temperature, or reduced seasonality. Each of these may provide interesting variables to consider. However, anuran diversity was the best variable to consider within the constraints of the available data, as it provides a broad measure of the encounter rate of one anuran with another, and hence predation opportunity.

Habitat

The habitat type in which each species occurred demonstrates the importance of generalists over all but shrubland species as amphibian predators, despite the fact that more species were found in forest than in any other habitat type. Forest habitats are physically complex and three dimensional, such that while there may be many species present, there may also be significant spatial separation (Williams and Hero 1998), as well as escape opportunities and refugia available to the prey. However, generalist species appear to prey on frogs both in forests and in

272 the other habitat categories.

274 Konopik et al. (2014) documented an invasion of forested habitat by generalist anurans in

275 Borneo which is particularly insightful. Following road construction, several species not known to 276 inhabit the forest quickly moved in with one newcomer found to consume significantly more 277 anurans than its resident congener. Interestingly, the authors found that these frogs were 278 matched for body size, but that the newcomer had a significantly larger gape (see above). 279

\section{Invasiveness}

281 Invasive frogs are generally claimed to have a negative impact on native species through a 282 number of mechanisms including, competition, hybridisation and predation (Bucciarelli et al. 
283

284

285

286

287

288

289

290

291

292

293 Taxonomy

294

295

296

297

298

299

300

301

302

303

304

305

306

307

308

309

310

311

312

313

314

315 316

2014; Kraus et al. 2011). The significance of predation has rarely been quantified, but is often listed as a threat to indigenous anurans. Our finding that invasive frogs have a higher proportion of anurans in their diet gives substance to this claim. Surprisingly, invasiveness was included in the best model in our study despite the small number of studies of the diets of invasive anurans that were available. Also, it was not confounded by the significant taxonomic signal in anuran predation, especially as our data included many studies on Rhinella marina, a bufonid which appears to rarely eat other anurans (see below). These results suggest that (non-bufonid) invasive frog species should be considered as an important threat in terms of their direct predatory effects on other anurans.

Emerson (1985) predicted that vertebrate-eating frogs would have a large gape (a wide skull with long jaws) and a high jaw closing force (longer jaws posterior to adductor insertion). Her data, based on a literature review, suggest a strong taxonomic bias to prey type, and she emphasised the relationship with skull morphology. Toledo et al. (2007) described anuran predators (including post-metamorphic anurans) as 'convenience predators', adding that “...the most representative predators are those who exhibit similar habits to the anurans, facilitating their encounters." Encounters would be expected to be higher amongst pond or stream dwelling species than among those which only visit these habitats for reproduction, such as many large bufonids. In a post hoc analysis within the superfamily Hyloidea we confirm that the Bufonidae are negligible predators of anurans while the families Ceratophryidae, Hylidae and Leptodactylidae all have elevated levels of anurophagy (Fig 1b). Indeed, the Ceratophryidae appear to regularly ingest anurans as well as other vertebrates (Schalk et al 2014).

Our post hoc tests suggest that bufonids and dendrobatids might be unusual families within the Hyloidea. Caldwell (1996) discussed the evolution of myrmecophagy in dendrobatids, and Isacch \& Barg (2002) investigated whether bufonids are also specialised ant-feeders, confirming that they tend to have smaller prey sizes than sympatric anurans in Argentina. Diesmos et al. (2008) reviewed impacts of invasive frogs in the Philippines and highlighted the differences between the anuran eating behaviour of the ranid, Hoplobatrachus rugulosus compared to a largely invertebrate diet in $R$. marina. Undoubtedly, $R$. marina can and does consume other anurans (Lever 2001; Wells 2007; Pizzatto \& Shine 2008), but it appears that this and other toad species do not have a large proportion of anurans in their diets. 
317 Synergy of habitat, species diversity, invasiveness and size

318 Our model suggests that our chosen variables are synergistic, with the combination of them 319 being more likely to result in anuran predation by frogs. This suggests that previous workers 320 who considered size or taxonomy alone had not appreciated that the conditions under which 321 anuran predation by frogs occurs is considerably more complex, and also involves variables that 322 describe the animals' habitat and opportunities available to prey on other anurans. A few 323 studies have provided insight into this complexity: Studies on predation by Lithobates 324 catesbeianus found that it commonly consumed many other anurans, but not necessarily in 325 proportion to their abundance (Boelter et al 2012; Werner et al 1995), implying that this species 326 is a habitat-specific convenience predator. In their study, Boelter et al. (2012) found that relative 327 size was important, although all sizes of bullfrogs consumed anurans: that is, both gape and 328 size appear important. In addition, these authors noted the low incidence of cannibalism, and 329 ascribed it to the higher diversity of sympatric species; equivalent to our species diversity 330 variable. However, the explanatory variables we could include in our study were tightly 331 constrained by the need for uniform availability across the entire dataset (see below). Therefore 332 we acknowledge that body size, species diversity, habitat and invasiveness may represent 333 proxies for more biologically meaningful variables that we were not able to score.

334

335

Cannibalism

336 Some anurans are known for cannibalism by adults on earlier life-history stages;

337 heterocannibalism (see Polis \& Myers 1985 for a review). In our data, eggs featured less 338 prominently in heterocannibalism than did tadpoles, but this may be due to a combination of 339 accessibility and the difference in period that each life-history stage is available. For example, 340 frogs in the genus Xenopus are often confined in water bodies with conspecific eggs and 341 tadpoles, and at times when these are abundant, they make up a large proportion of the prey 342 eaten (Measey 1998). Generally, we found pipids to be notable by their high levels of predation 343 on eggs and tadpoles, although this is not confined to conspecifics. Pipids lack a tongue and 344 rely on suction for most small prey items, although they are also able to take large prey through 345 jaw prehension (Carreño \& Nishikawa 2010).

346

347 Egg predation is not confined to aquatic anurans, frogs in the genus Afrixalus are associated 348 with egg predation on conspecific as well as heterospecific eggs (Drewes \& Altig 1996). Again, 349 levels of predation can become significant when this prey type is in abundance (Dayton \& 350 Fitzgerald 2006; Marshall et al. 1990; Vonesh 2005). In our dataset, Pelophylax ridibundus, 
351 Eleutherodactylus coqui and E. planirostris were also reported to cannibalise brood (Beard 352 2007; Olson \& Beard 2012; Ruchin \& Ryzhov 2002). Brood sites for Eleutherodactylus species 353 are in fallen leaves that capture small quantities of water, allowing other adults to easily access 354 and cannibalise them. Drewes \& Altig (1996) provide a number of anecdotal accounts of adult 355 frogs consuming eggs, and we agree with their conclusion that this may be far more common 356 than reported, although temporally limited by the transient availability of this prey type. 357

Terrestrial anuran species predated on tadpoles far more commonly that would be expected for 359 species that rely on lingual protraction for prey capture (O'Reilly et al. 2002). Given that this feeding mode is not effective for most aquatic prey, it appears that jaw prehension is not an unusual mechanism for many post-metamorphic frogs. Again, it is noteworthy that the majority of cases occur in the ranids (with some instances of leptodactylids eating tadpoles), and that these made up a significant proportion of prey. In one study on the diet of the African Tiger Frog, Hoplobatrachus occipitalis, the authors found that many of the prey items had an aquatic origin with fish making up the largest proportion of prey items as well as large numbers of tadpoles (Hirschfeld \& Roedel 2011). Our data suggest that aquatic ingestion, presumably by jaw prehension, is not uncommon in frogs, and we suggest that this requires further study.

In the literature we surveyed, the life-history stage most commonly eaten by frogs was postmetamorphic individuals. There are reports that eating anurans that are large in relation to the predatory frog may result in excessive handling time, as well as a risk of injury to the individual predator (Wyatt \& Forys 2004). This corroborates our finding that body size is a strong predictor of anurophagy. Unfortunately, we could not test for size differences between frogs consuming and being consumed, as these data were recorded in only a handful of studies. However other studies have found larger individuals are significantly more likely to eat smaller ones (Toledo et al. 2007).

\section{Conservation Management}

379 Our study provides important insight into amphibian conservation management with respect to 380 direct predation effects. Clearly, there is the important threat from invasive species, which our 381 study suggests has taxonomic bias. In a post hoc test excluding all records of members of the 382 family Bufonidae, the effect of invasive species increased to invasive frogs being $31.9 \%$ more 383 likely to consume anurans (full glm model with all variables se $=0.07$ ). Managers might also expect that the behaviour of large frogs may change if the habitat is disturbed, especially in 
385

386

387

388

389

390

391

392

393

394

395

396

397

398

399

400

401

402

403

404

405

406

407

408

409

410

411

412

413

414

415

417

418

\section{Constraints}

\section{Conclusions}

We find that the consumption of anurans by post-metamorphic frogs is not unusual at the

situations where amphibian diversity is high. Furthermore, our traits may be useful in scores on risk assessments when considering which amphibians should not be traded. Many countries are drawing up lists of species that should not be traded, and these are largely based on species that are already invasive elsewhere. The results of our study suggest that avoiding trade in large ranid (and pipid) generalists would appear to be prudent, and that this may be especially important for countries with high amphibian diversity.

There were a large number of papers that we could not include in our study due to the lack of uniform variables. Most commonly, investigators reported on statistically derived figures representing prey proportions or indices, without inclusion of, or any way to calculate back to, the raw data. The importance of including raw data in manuscripts (or at least in supplementary information) is invaluable in making such data available for additional studies (such as this one, but see also Vignoli \& Luiselli 2012).

Our study probably underestimates the importance of anurophagy when it occurs. For example, we did not consider any anurophagy that takes place before metamorphosis, although this is recognised as being of great importance, especially with respect to cannibalism (see Altig et al 2007; Polis \& Myers 1985). Further, we chose to represent the importance of anurans in the diet of frogs as a proportion of total prey items ingested, because data on prey volume was missing from the majority of studies. The proportion of total prey items provides no clear indication of what volume anurans made up in the stomachs of individuals or even at a population level. Some authors have addressed the volumetric contribution or contribution by mass of different prey items, and these generally increase the importance of large items, such as frogs (e.g. Boelter et al. 2012). Lastly, the data available to us in the dietary studies we used rarely quantified behavioural traits of frog predators such as activity patterns and foraging mode. These likely remain important and largely underexplored topics with respect to anurophagy (see Schalk \& Fitzgerald 2015). population level, but does have a strong taxonomic bias. A high proportion of frogs in the diet is predicted for animals that are large, invasive, generalists, and live in areas with many other 
419

420

421

422

423

424

425

426

427

428

429

430

431

432

433

434

435

436

437

438

439

440

441

442

443

444

445

446

447

448

449

450

451

452

453

454

455

456

457

458

459

amphibian species. Our study was limited by the type of available data, and future investigations may need to focus on traits such as gape, density and predator behaviour to better refine incidents of anurophagy. The limited number of studies on invasive amphibian diet suggests that they commonly eat other anurans, and it seems reasonable to assume that invasive pipids and ranids may be expected to have an adverse effect on local amphibian communities. This should be taken into account in pre-border risk assessments of these taxa. Overall we found a small number of papers available on invasive anuran diets, and we specifically encourage more studies on the impacts of invasive anurans.

\section{Acknowledgements}

We would like to thank the authors who kindly provided us with data not originally published with their studies. In addition, we'd like to thank Solveig Vogt, Marie Theron and James Vonesh for their help with literature and critical reading of the manuscript. GJM \& RA would like to thank the NRF for incentive funding. Two reviewers gave insightful comments that improved the manuscript.

\section{References:}

Altig R, Whiles MR, and Taylor CL. 2007. What do tadpoles really eat? Assessing the trophic status of an understudied and imperiled group of consumers in freshwater habitats. Freshwater Biology 52:386-395.

Beard KH. 2007. Diet of the invasive frog, Eleutherodactylus coqui, in Hawaii. Journal Information 2007.

Boelter RA, Kaefer IL, Both C, and Cechin S. 2012. Invasive bullfrogs as predators in a Neotropical assemblage: What frog species do they eat? Animal Biology 62:397-408.

Bonetti MF, and Wiens JJ. 2014. Evolution of climatic niche specialization: a phylogenetic analysis in amphibians. Proceedings of the Royal Society B: Biological Sciences 281:20133229.

Brose U, Jonsson T, Berlow EL, Warren P, Banasek-Richter C, Bersier L-F, Blanchard JL, Brey T, Carpenter SR, and Blandenier M-FC. 2006. Consumer-resource body-size relationships in natural food webs. Ecology 87:2411-2417.

Bucciarelli GM, Blaustein AR, Garcia TS, and Kats LB. 2014. Invasion Complexities: The Diverse Impacts of Nonnative Species on Amphibians. Copeia 2014:611-632.

Burton TM, and Likens GE. 1975. Energy flow and nutrient cycling in salamander populations in the Hubbard Brook Experimental Forest, New Hampshire. Ecology:1068-1080.

Caldwell JP. 1996. The evolution of myrmecophagy and its correlates in poison frogs (Family Dendrobatidae). Journal of Zoology 240:75-101.

Caldwell JP, and Vitt LJ. 1999. Dietary asymmetry in leaf litter frogs and lizards in a transitional northern Amazonian rain forest. Oikos:383-397.

Carreño CA, and Nishikawa KC. 2010. Aquatic feeding in pipid frogs: the use of suction for prey capture. The Journal of experimental biology 213:2001-2008. 
460

461

462

463

464

465

466

467

468

469

470

471

472

473

474

475

476

477

478

479

480

481

482

483

484

485

486

487

488

489

490

491

492

493

494

495

496

497

498

499

500

501

502

503

504

505

506

507

508

509

Cohen JE, Pimm SL, Yodzis P, and Saldaña J. 1993. Body sizes of animal predators and animal prey in food webs. Journal of Animal Ecology:67-78.

Colón-Gaud C, Whiles MR, Kilham SS, Lips KR, Pringle CM, Connelly S, and Peterson SD. 2009. Assessing ecological responses to catastrophic amphibian declines: patterns of macroinvertebrate production and food web structure in upland Panamanian streams. Limnology and Oceanography 54:331-343.

Conradie W, Branch WR, Braack H, and Manson M. 2010. Notes on the diet of recently metamorphosed Giant African Bullfrogs (Anura: Pyxicephalidae: Pyxicephalus adspersus) and growth increase during the first nine months in a semi-natural habitat. Herpetology Notes 3:215-219.

Dayton GH, and Fitzgerald LA. 2006. Habitat suitability models for desert amphibians. Biological Conservation 132:40-49.

Diesmos AC, Diesmos ML, and Brown R. 2008. Status and distribution of alien invasive frogs in the Philippines. Journal of Environmental Science and Management 9.

Drewes R, and Altig R. 1996. Anuran egg predation and heterocannibalism in a breeding community of East African frogs. Tropical Zoology 9:333-347.

Emerson SB. 1985. Skull shape in frogs: correlations with diet. Herpetologica:177-188.

Ficetola GF, Rondinini C, Bonardi A, Baisero D, and Padoa-Schioppa E. 2015. Habitat availability for amphibians and extinction threat: a global analysis. Diversity and Distributions 21:302-311.

Frost DR. 2015. Amphibian Species of the World: an Online Reference. Version 6.0. Available at http://research.amnh.org/herpetology/amphibia/index.html (accessed 01 May 2015 2015).

Gibbons JW, Winne CT, Scott DE, Willson JD, Glaudas X, Andrews KM, Todd BD, Fedewa LA, Wilkinson L, and Tsaliagos RN. 2006. Remarkable amphibian biomass and abundance in an isolated wetland: implications for wetland conservation. Conservation Biology 20:1457-1465.

Glorioso BM, Waddle JH, Crockett ME, Rice KG, and Percival HF. 2012. Diet of the invasive Cuban Treefrog (Osteopilus septentrionalis) in pine rockland and mangrove habitats in South Florida. Caribbean Journal of Science 46:346-355.

Halliday, T. R. 2008. Why amphibians are important. International Zoo Yearbook 42:7-14.

Hirschfeld M, and Roedel M-O. 2011. The diet of the African Tiger Frog, Hoplobatrachus occipitalis, in northern Benin. Salamandra 47:125-132.

Hof C, Araújo MB, Jetz W, and Rahbek C. 2011. Additive threats from pathogens, climate and land-use change for global amphibian diversity. Nature 480:516-519.

Isacch JP, and Barg M. 2002. Are bufonid toads specialized ant-feeders? A case test from the Argentinian flooding pampa. Journal of Natural History 36:2005-2012.

Kats LB, and Ferrer RP. 2003. Alien predators and amphibian declines: review of two decades of science and the transition to conservation. Diversity and Distributions 9:99-110.

Kiesecker JM. 2003. Invasive species as a global problem: toward understanding the worldwide decline of amphibians. In: Semlitsch RD, ed. Amphibian Conservation. Washington, D.C.: Smithsonian Institution Press, 113-126.

Konopik O, Linsenmair K-E, and Grafe TU. 2014. Road construction enables establishment of a novel predator category to resident anuran community: a case study from a primary lowland Bornean rain forest. Journal of Tropical Ecology 30:13-22.

Kraus JM, Pletcher LT, and Vonesh JR. 2011. Variation in active and passive resource inputs to experimental pools: mechanisms and possible consequences for food webs. Freshwater Biology 56:491-502.

Lever C. 2001. The cane toad: the history and ecology of a successful colonist. London: Westbury Academic \& Scientific Pub.. 
510

511

512

513

514

515

516

517

518

519

520

521

522

523

524

525

526

527

528

529

530

531

532

533

534

535

536

537

538

539

540

541

542

543

544

545

546

547

548

549

550

551

552

553

554

555

556

557

558

559

560

Marshall C, Doyle L, and Kaplan R. 1990. Intraspecific and sex-specific oophagy in a salamander and a frog: reproductive convergence of Taricha torosa and Bombina orientalis. Herpetologica:395-399.

McCoy MW, Barfield M, and Holt RD. 2009. Predator shadows: complex life histories as generators of spatially patterned indirect interactions across ecosystems. Oikos 118:87100.

Measey G. 1998. Diet of feral Xenopus laevis (Daudin) in South Wales, UK. Journal of Zoology 246:287-298.

O'Reilly JC, Deban SM, and Nishikawa KC. 2002. Derived life history characteristics constrain the evolution of aquatic feeding behavior in adult amphibians. In Topics in functional and ecological vertebrate morphology,(Eds.) pp 153-190. In: Aerts P, D’Août K, Herrel A, and Damme RV, eds.

Olson CA, and Beard KH. 2012. Diet of the introduced greenhouse frog in Hawaii. Copeia 2012:121-129.

Pizzatto L and Shine R. 2008. The behavioral ecology of cannibalism in cane toads (Bufo marinus). Behavioral Ecology and Sociobiology 63:123-133.

Polis GA, and Myers CA 1985. A survey of intraspecific predation among reptiles and amphibians. Journal of Herpetology 19:99-107.

Pyron RA. 2014. Biogeographic analysis reveals ancient continental vicariance and recent oceanic dispersal in amphibians. Systematic biology:syu042.

Pyron RA, and Wiens JJ. 2011. A large-scale phylogeny of Amphibia including over 2800 species, and a revised classification of extant frogs, salamanders, and caecilians. Molecular Phylogenetics and Evolution 61:543-583.

Regester KJ, Lips KR, and Whiles MR. 2006. Energy flow and subsidies associated with the complex life cycle of ambystomatid salamanders in ponds and adjacent forest in southern Illinois. Oecologia 147:303-314.

Ruchin AB, and Ryzhov MK. 2002. On the diet of the marsh frog (Rana ridibunda) in the Sura and Moksha watershed, Mordovia. Advances in Amphibian Research in the Former Soviet Union 7:197-205.

Semlitsch RD, O'Donnell K, and Thompson III F. 2014. Abundance, biomass production, nutrient content, and the possible role of terrestrial salamanders in Missouri Ozark forest ecosystems. Canadian Journal of Zoology 92:997-1004.

Schalk CM, Montaña CG, Klemish JL, and Wild ER 2014. On the diet of the frogs of the Ceratophryidae: Synopsis and new contributions. South American Journal of Herpetology 9:90-105.

Schalk C and Fitzgerald LA (2015). Ontogenetic shifts in ambush site selection of a sit-and-wait predator, the Chacoan Horned Frog (Ceratophrys cranwelli, Anura: Ceratophryidae). Canadian Journal of Zoology 93:461-467.

Toft CA. 1985. Resource partitioning in amphibians and reptiles. Copeia:1-21.

Toledo LF, Ribeiro R, and Haddad CF. 2007. Anurans as prey: an exploratory analysis and size relationships between predators and their prey. Journal of Zoology 271:170-177.

Verburg P, Kilham SS, Pringle CM, Lips KR, and Drake DL. 2007. A stable isotope study of a neotropical stream food web prior to the extirpation of its large amphibian community. Journal of Tropical Ecology 23:643-651.

Vignoli L, and Luiselli L. 2012. Dietary relationships among coexisting anuran amphibians: a worldwide quantitative review. Oecologia 169:499-509.

Vonesh JR. 2005. Egg predation and predator-induced hatching plasticity in the African reed frog, Hyperolius spinigularis. Oikos 110:241-252.

Wakano J, Kohmatsu Y, and Yamamura N. 2002. Evolutionary dynamics of frequencydependent growth strategy in cannibalistic amphibians. Evolutionary ecology research 4:719-736. 
561 Wells KD. 2007. The ecology and behavior of amphibians: University of Chicago Press. bullfrogs and green frogs: implications for interspecific predation and competition. Journal of Herpetology 29:600-607.

Williams SE and Hero JM. 1998. Rainforest frogs of the Australian Wet Tropics: guild classification and the ecological similarity of declining species.Proceedings of the Royal Society of London B: Biological Sciences 265:597-602.

Woodward G, Ebenman B, Emmerson M, Montoya JM, Olesen JM, Valido A, and Warren PH. 2005. Body size in ecological networks. Trends in ecology \& evolution 20:402-409.

Woolbright LL, Hara AH, Jacobsen CM, Mautz WJ, and Benevides Jr FL. 2006. Population densities of the coqui, Eleutherodactylus coqui (Anura: Leptodactylidae) in newly invaded Hawaii and in native Puerto Rico. Journal of Herpetology 40:122-126.

Wyatt JL, and Forys EA. 2004. Conservation implications of predation by Cuban treefrogs (Osteopilus septentrionalis) on native hylids in Florida. Southeastern Naturalist 3:695-

576 700.

577 
578 Table 1 Generalised Linear Models with binomial errors and a logit link function run on proportion of frogs 579 eaten (eggs + tadpoles + post-metamorphic individuals and total non-anuran prey: 'prop') in relation to

580 whether populations were 'invasive', the 'habitat' the species is found in, the size of the species ('SVL'), 581 and the diversity of species at the site where the study was conducted ('spp': see methods for details of 582 variable calculations). Each model was run with 'superfamily' as a fixed effect. $\triangle A I C$ is the difference in

583 Akaike Information Criterion values (AIC) between the current model and the best, wi is the relative

584 support a model has from the data compared to the other models in the set: Akaike weight. $\mathrm{K}$ is the 585 number of parameters in the model.

586 
587 Figure 1 The proportion of frogs eaten in the diet of other frogs divided up by superfamily ( $\mathrm{n}$ values are 588 given below superfamily names). The box-plot shows the significant increase in anurans in the diets of 589 pipids and ranid frogs. Individual data points are added (with a jitter effect to prevent overlapping), and 590 show the range of data in all groups. (b) Inset: Data for the superfamily Hyloidea, broken down to show 591 the effects of families ( $\mathrm{n}$ values are given below family names). The families Ceratophryidae,

592 Leptodactylidae, and Hylidae have large proportions while smaller proportions are eaten by Bufonidae 593 (the single outlier is a study on invasive Rhinella marina) and Dendrobatidae.

594

595 
596 Figure 2 The proportion of frogs eaten in the diet of other frogs divided by predator habitat. The box plot 597 shows the significantly higher incidence of anurans in the diets of generalists over frogs from other

598 habitats ( $\mathrm{n}$ values are given below habitat categories). Individual data points are added (with a jitter effect 599 to prevent overlapping), and show the range of data in all groups.

600

601

602

603 


\section{Table $\mathbf{1}_{\text {(on next page) }}$}

Modelled variables explaining anurophagy

Generalised Linear Models with binomial errors and a logit link function run on proportion of frogs eaten (eggs + tadpoles + post-metamorphic individuals and total non-anuran prey: 'prop') in relation to whether populations were 'invasive', the 'habitat' the species is found in, the size of the species ('SVL'), and the diversity of species at the site where the study was conducted ('spp': see methods for details of variable calculations). Each model was run with 'superfamily' as a fixed effect. $\triangle \mathrm{AIC}$ is the difference in Akaike Information Criterion values (AIC) between the current model and the best, wi is the relative support a model has from the data compared to the other models in the set: Akaike weight. $\mathrm{K}$ is the number of parameters in the model. 
1 Table 1 Generalised Linear Models with binomial errors and a logit link function run on proportion of frogs

2 eaten (eggs + tadpoles + post-metamorphic individuals and total non-anuran prey: 'prop') in relation to

3 whether populations were 'invasive', the 'habitat' the species is found in, the size of the species ('SVL'),

4 and the diversity of species at the site where the study was conducted ('spp': see methods for details of

5 variable calculations). Each model was run with 'superfamily' as a fixed effect. $\triangle \mathrm{AIC}$ is the difference in

6 Akaike Information Criterion values (AIC) between the current model and the best, $w i$ is the relative

7 support a model has from the data compared to the other models in the set: Akaike weight. $\mathrm{K}$ is the

8 number of parameters in the model.

9

\begin{tabular}{|c|c|c|c|c|c|}
\hline $\begin{array}{l}\text { Model } \\
\text { number }\end{array}$ & Model name & $\begin{array}{l}\text { log- } \\
\text { likelihood }\end{array}$ & $\mathrm{K}$ & $\Delta(\mathrm{AIC})$ & wi \\
\hline 4 & spp & -2444.33 & 6 & 1502.096 & 0 \\
\hline 2 & habitat & -2369.12 & 8 & 1355.662 & 2.93E-295 \\
\hline 6 & habitat + spp & -2320.74 & 9 & 1260.91 & 1.10E-274 \\
\hline 1 & invasive & -2170.55 & 6 & 954.5391 & 3.71E-208 \\
\hline 10 & invasive + habitat & -2138.69 & 9 & 896.8023 & $1.28 \mathrm{E}-195$ \\
\hline 5 & invasive $+\mathrm{spp}$ & -2081.61 & 7 & 778.658 & $5.78 \mathrm{E}-170$ \\
\hline 13 & spp + invasive + habitat & -2025.5 & 10 & 672.4358 & $6.73 E-147$ \\
\hline 3 & SVL & -1793.04 & 6 & 199.5074 & $3.33 E-44$ \\
\hline 7 & SVL + invasive & -1791.21 & 7 & 197.8459 & 7.65E-44 \\
\hline 9 & SVL + habitat & -1780.9 & 9 & 181.2266 & $3.11 \mathrm{E}-40$ \\
\hline 12 & SVL + invasive + habitat & -1777.85 & 10 & 177.1206 & $2.42 \mathrm{E}-39$ \\
\hline 8 & $S V L+s p p$ & -1702.88 & 7 & 21.19062 & $1.75 \mathrm{E}-05$ \\
\hline 14 & SVL + spp + habitat & -1698.55 & 10 & 18.52097 & $6.66 \mathrm{E}-05$ \\
\hline 11 & SVL + spp + invasive & -1692.14 & 8 & 1.700938 & 0.299309 \\
\hline 15 & SVL + spp + invasive + habitat & -1688.28 & 11 & 0 & 0.700607 \\
\hline
\end{tabular}

10 


\section{Figure 1 (on next page)}

Taxonomic bias in anurophagy across superfamilies (and Hyloidea)

Figure 1 The proportion of frogs eaten in the diet of other frogs divided up by superfamily ( $\mathrm{n}$ values are given below superfamily names). The box-plot shows the significant increase in anurans in the diets of pipids and ranid frogs. Individual data points are added (with a jitter effect to prevent overlapping), and show the range of data in all groups. (b) Inset: Data for the superfamily Hyloidea, broken down to show the effects of families ( $n$ values are given below family names). The families Ceratophryidae, Leptodactylidae, and Hylidae have large proportions while smaller proportions are eaten by Bufonidae (the single outlier is a study on invasive Rhinella marina) and Dendrobatidae. 
PeerJReviewing Manuscript

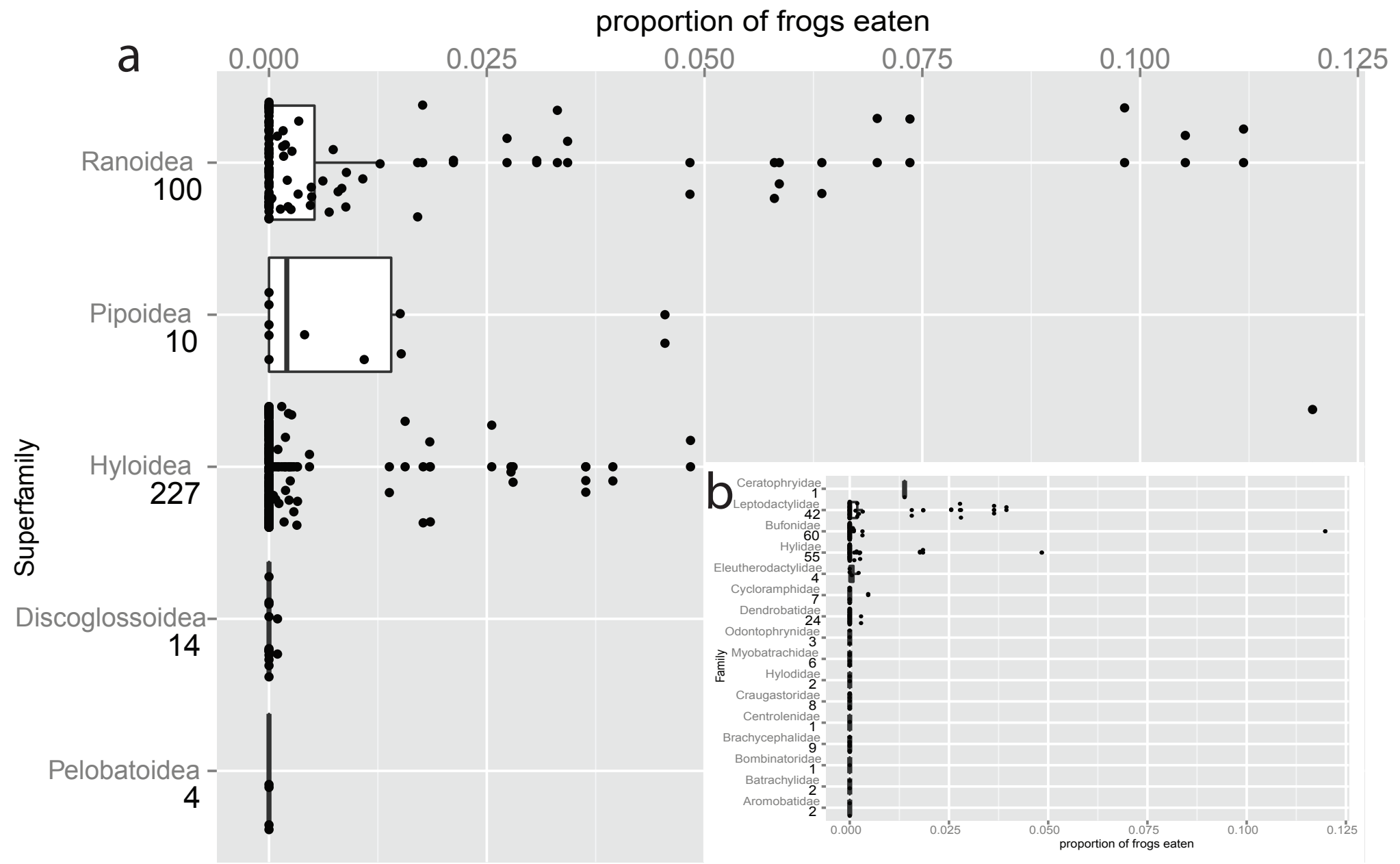


Figure $\mathbf{2}$ (on next page)

Habitat influence on anurophagy

Figure 2 The proportion of frogs eaten in the diet of other frogs divided by predator habitat. The box plot shows the significantly higher incidence of anurans in the diets of generalists over frogs from other habitats ( $\mathrm{n}$ values are given below habitat categories). Individual data points are added (with a jitter effect to prevent overlapping), and show the range of data in all groups. 
